\title{
LONG-TERM RESULTS OF SURGICAL TREATMENT FOR MITRAL REGURGITATION WITH SEVERE LEFT VENTRICULAR DYSFUNCTION AFTER MYOCARDIAL INFARCTION CAUSED BY KAWASAKI DISEASE
}

\author{
Toshiki Takahashi, MD, Keishi Kadoba, MD, Kazuhiro Taniguchi, MD, Hiroshi Imagawa, MD, Tetsuya Sano, MD, \\ Yasuhisa Shimazaki, MD, and Hikaru Matsuda, MD, Osaka, Japan
}

Cardiovascular involvement is the major cause of morbidity and mortality among children with Kawasaki disease. ${ }^{1}$ Mitral regurgitation (MR) is one of the major determinants of long-term survival after myocardial infarction caused by Kawasaki disease. ${ }^{2}$ Only a few reports discuss surgical treatment for this cardiac abnormality, however, and its long-term results have been unknown, ${ }^{3-4}$ especially in patients with severe left ventricular (LV) dysfunction. In this report, we describe two cases of Kawasaki disease with refractory congestive heart failure caused by massive MR after myocardial infarction, as well as long-team results of surgical treatment (Table I).

\section{Case reports}

CASE 1. A 2-year-old boy underwent mitral valve replacement for MR after an inferior myocardial infarction. He had complete obstruction of the right coronary artery (RCA). This patient's operative findings and early postoperative course are reported elsewhere ${ }^{3}$ Cardiac catheterization and angiographic studies 4 months after operation demonstrated sustained pulmonary hypertension and severe LV dysfunction despite symptomatic improvement. When the patient was 6 years old, prosthetic valve dysfunction developed, necessitating another mitral valve replacement with a Björk-Shilley mechanical valve. He has been free from any cardiac event and has been conducting almost normal daily life for more than next 10 years since the second operation. Noninvasive cardiac evaluations at the age of 16 years showed no pulmonary hypertension and improvement in $\mathrm{LV}$ pump function of $46 \%$ in ejection fraction. Exercise thallium 201 myocardial scintigraphy showed persistent perfusion defects in the inferior lesion and reversed distribution in the anterior lesion. Holter electrocardiographic monitoring showed multifocal ventricular premature beats, including a salvo of monofocal beats classified as Lown's grade 4B, for which an antiarrhythmic agent has been administered.

From the First Department of Surgery and the Department of Pediatrics, Osaka University Medical School, Osaka, Japan.

Received for publication Aug. 22, 1995; accepted for publication Sept. 13, 1995.

J Thorac Cardiovasc Surg 1996;111:893-4

Copyright (C) 1996 by Mosby-Year Book, Inc.

$0022-5223 / 96 \$ 5.00+0 \quad \mathbf{1 2 / 5 4 / 6 9 2 6 1}$
CASE 2. A 3-year-old boy had refractory congestive heart failure after an inferior myocardial infarction that occurred in the acute phase of Kawasaki disease. Cardiac catheterization and angiographic studies confirmed complete obstruction of the large RCA, giant aneurysms without stenosis of the left main trunk and anterior descending coronary artery, massive MR, severe pulmonary hypertension, and severe LV dysfunction with an extended akinesis in the inferoposterior lesions. Thallium 201 myocardial scintigraphy showed extended perfusion defect in these lesions, compatible with the distribution of the large RCA. Maximum antifailure treatment failed to improve his clinical condition, so surgical intervention on the mitral valve without coronary revascularization was indicated. The patient underwent mitral annuloplasty with semicircular suture plication. The mitral valve had a remarkably dilated anulus ( $30 \mathrm{~mm}$ in diameter) but showed little inflammatory change of the leaflets. The valve apparatus at posteromedial area had become sparse and thinned out; in particular, the posteromedial papillary muscle did not seem to retain any muscle component. He had persistent moderate heart failure and respiratory distress for awhile after operation. Cardiac catheterization and angiographic studies 2 months after operation demonstrated sustained pulmonary hypertension, severe LV dysfunction with $23 \% \mathrm{LV}$ ejection fraction, and a mild degree of MR. He eventually had a good convalescence, however, and was discharged 3 months after operation. Cardiac catheterization and angiographic studies 1 year after operation showed improvement of pulmonary hypertension and recanalization of the RCA. Holter electrocardiographic monitoring showed monofocal ventricular premature beats classified as Lown's grade 2. Diuretics, vasodilators, and antiplatelet agents have been administered, and the patient has conducted an uneventful daily life during a follow-up period of 3 years.

\section{Discussion}

From the intraoperative findings of transmural inferior myocardial infarction with papillary muscle necrosis and markedly dilated anulus without inflammatory change of the leaflets, ${ }^{3}$ the pathogenesis of MR in our patients seemed to be a combination of papillary muscle dysfunction and generalized annular dilatation. The first patient had more severe LV dysfunction for the size of the distribution of his involved RCA. Postoperative myocardial scintigraphy suggested myocardial injury in the uninvolved left anterior descending coronary artery lesion 
Table I. Cardiac catheterization and angiographic studies performed in two children with Kawasaki disease before and after mitral valve operations for ischemic MR

\begin{tabular}{|c|c|c|c|c|c|c|c|}
\hline & \multicolumn{4}{|c|}{ Cardiac catheterization } & \multicolumn{2}{|c|}{ Coronary angiography } & \multirow[b]{2}{*}{$\begin{array}{c}\text { Holter } \\
E C G\end{array}$} \\
\hline & $\begin{array}{c}m P A \\
(m m H g)\end{array}$ & $\stackrel{C I}{\left(l \cdot \min ^{-1} \cdot m^{-2}\right)}$ & $\begin{array}{c}\text { LVESVI } \\
\left(\mathrm{ml} / \mathrm{m}^{2}\right)\end{array}$ & $\begin{array}{c}\text { LVEF } \\
(\%)\end{array}$ & $R C A$ & $\angle A D$ & \\
\hline \multicolumn{8}{|l|}{ Case 1} \\
\hline Before 1st operation & 48 & 2.9 & 135 & 35 & Occluded & Dilatation & \\
\hline 4 mo after 1 st operation & 54 & 4.2 & 140 & 26 & Occluded & Normal & \\
\hline 5 yr after 1 st operation* & 35 & 4.2 & 117 & 33 & Occluded & Normal & \\
\hline 14 yr after 1st operation & $\mathrm{PH}(-) \dagger$ & - & $81 \stackrel{1}{t}$ & $46 \%$ & Occluded & Normal & Lown 4B \\
\hline \multicolumn{8}{|l|}{ Case 2} \\
\hline Before operation & 33 & 2.6 & 109 & 34 & Occluded & Giant aneurysms & \\
\hline 2 mo after MAP & 40 & 3.1 & 136 & 23 & Occluded & Giant aneurysms & \\
\hline $1 \mathrm{yr}$ after MAP & 19 & 3.4 & 116 & 34 & Recanalized & Giant aneurysms & Lown 2 \\
\hline
\end{tabular}

$m P A$, Mean pulmonary artery pressure; $C I$, cardiac index; $L V E S V I, L V$ end-systolic volume index; $L V E F$, LV ejection fraction; $L A D$, left anterior descending coronary artery; $E C G$, electrocardiogram; $P H$, pulmonary hypertension; $M A P$, mitral annuloplasty.

"Before second repeat mitral valve replacement.

$\nmid$ By Doppler echocardiography.

$¥$ By radionuclide ventriculography.

caused by myocarditis resulting from Kawasaki disease. The extended myocardial damage with papillary muscle necrosis seemed to cause an vicious circle of $L V$ dilatation and severe MR. Only surgical treatment could relieve the intractable condition; little improvement was afforded by medical treatment. The clinical and hemodynamic statuses eventually improved after surgical intervention to achieve a competent mitral valve despite impaired LV function. The first patient had slight improvement in LV function during long-term follow-up, which may be attributable to the reduction of the proportion of the infarcted region with the growth of the residual LV muscle.

Recent reports ${ }^{5}$ suggested mitral valve repair can offer potential for improved therapeutic results even in patients with severe LV dysfunction, avoiding the detrimental effects of mitral apparatus destruction on $\mathrm{LV}$ function and significant long-term complications of prosthetic valves. Mitral valve repair should also be aggressively considered in children with massive MR from Kawasaki disease. The second patient had mild residual MR and giant aneurysm of the left coronary artery, which have potential for a fatal myocardial infarction. ${ }^{1}$ Further intensive follow-up will be required for this patient. In conclusion, surgical treatment can offer a potential for improvement of long-term prognosis in MR with severe
LV dysfunction after myocardial infarction caused by Kawasaki disease.

\section{REFERENCES}

1. Dajani AS, Taubert KA, Gerber MA, et al. Committee on Rheumatic Fever, Endocarditis, and Kawasaki Disease, Council on Cardiovascular Disease in the Young, American Heart Association: AHA medical/scientific statement: special report-diagnosis and therapy of Kawasaki disease in children. Circulation 1993;87:1776-80.

2. Kato H, Ichinose E, Kawasaki T. Myocardial infarction in Kawasaki disease: clinical analyses in 195 cases. J Pediatr 1986;108:923-7.

3. Kitamura S, Kawashima Y, Kawachi K, et al. Severe mitral regurgitation due to coronary arteritis of mucocutaneous lymph node syndrome: a new surgical entity. J THORAC CARDIOVASC SuRG 1980;80:629-36.

4. Kitamura S, Kawachi K, Oyama C, et al. Severe Kawasaki heart disease treated with an internal mammary artery graft in pediatric patients: a first successful report. J THORAC CARDIOVASC SURG 1985;89:860-6.

5. Rankin JS, Feneley MP, Hickey MS, et al. A clinical comparison of mitral valve repair versus valve replacement in ischemic mitral regurgitation. J THORAC CARDIOVASC SURG 1988; 95:165-77. 